\title{
A Novel Catechol-based Universal Support for Oligonucleotide Synthesis
}

Keith M. Anderson ${ }^{\ddagger \dagger}$, Laurent Jaquinod ${ }^{++}$, Michael A. Jensen ${ }^{\dagger}, \mathrm{Nam} \mathrm{Ngo}^{++}$, and Ronald W. Davis ${ }^{\dagger^{*}}$

${ }^{\dagger}$ Stanford Genome Technology Center, Stanford University, Palo Alto, California, 94304, USA

${ }^{++}$CTGen, Inc., Milpitas, California, 95035, USA

\section{Table of Contents:}

RP-HPLC Chromatogram of longmer oligonucleotides 


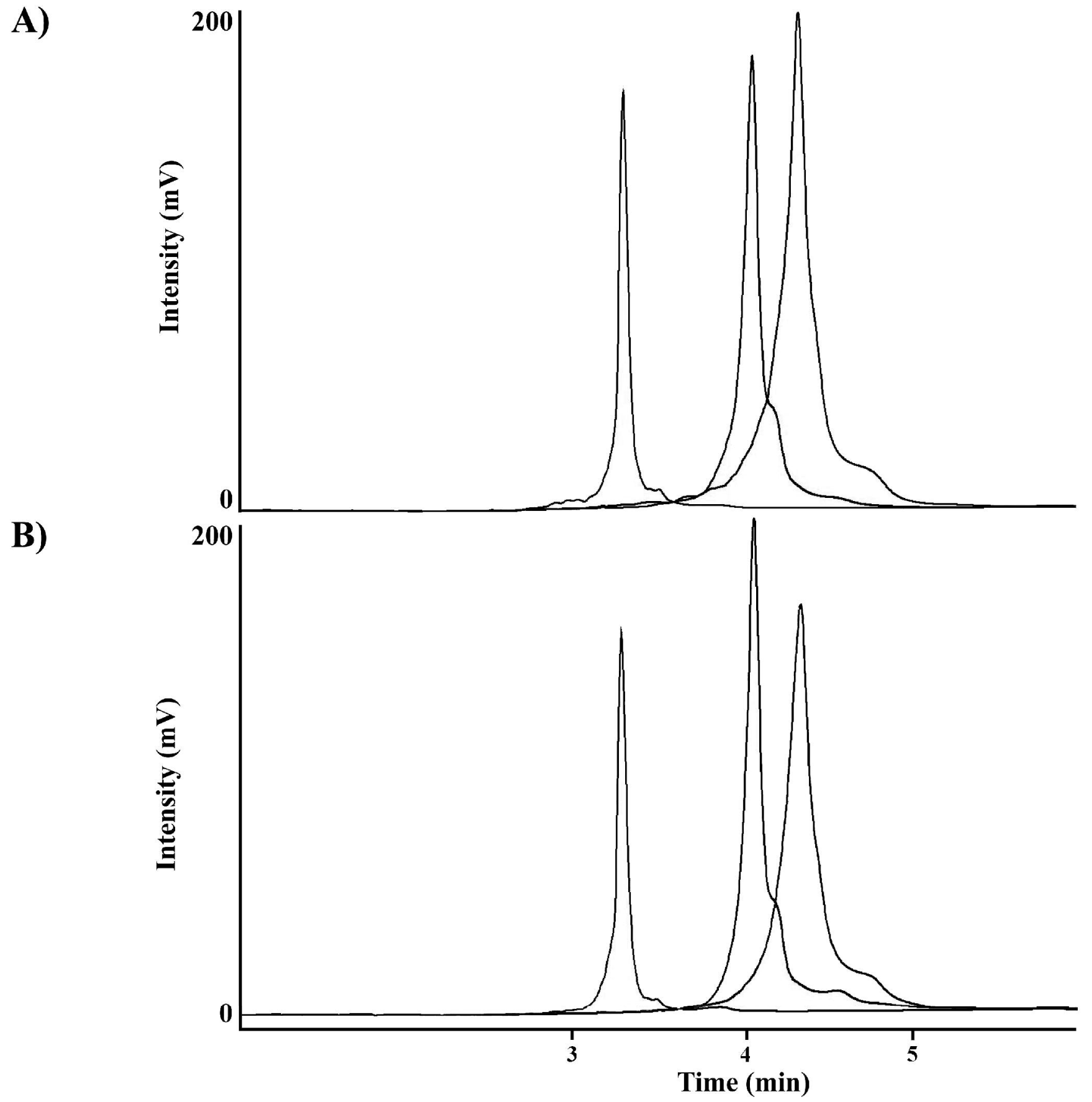

Figure 1. Chromatograms of a typical 40mer, 80mer, and 120mer synthesized on the best commercially available column we could find (A), and compared to those synthesized on the UL1 universal support column (B). 
A)

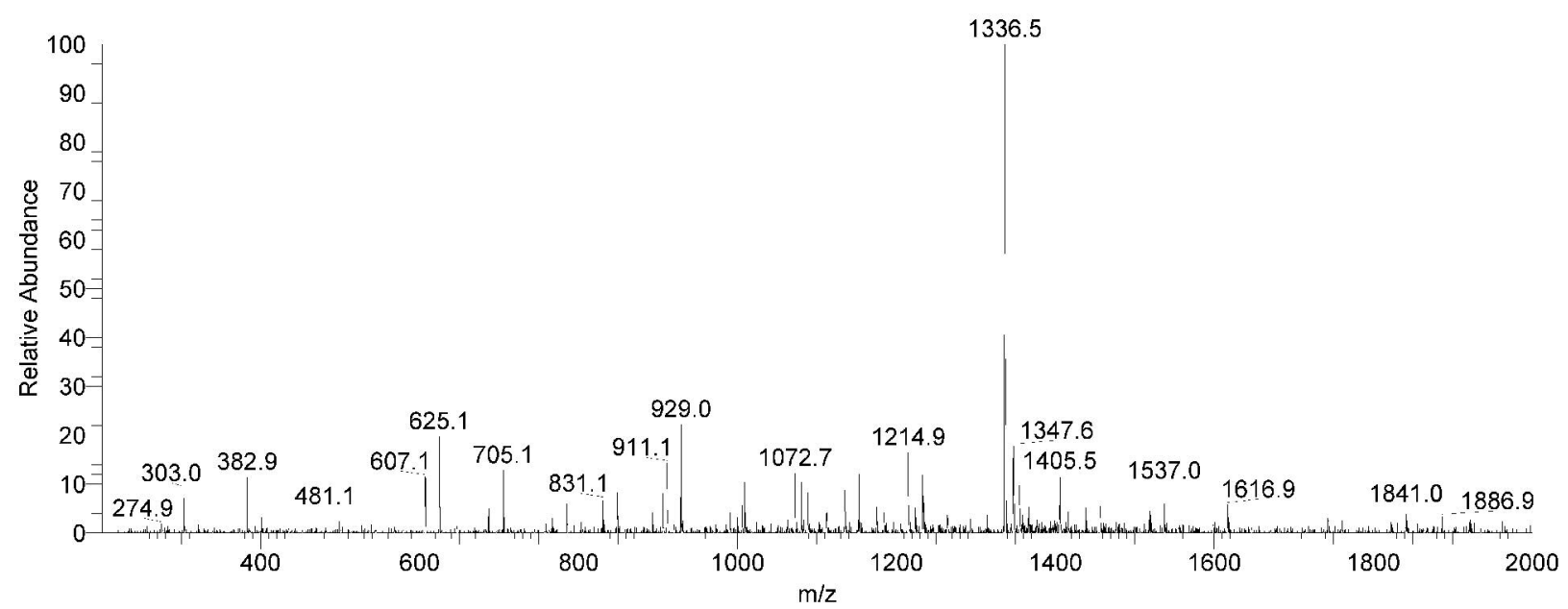

B)

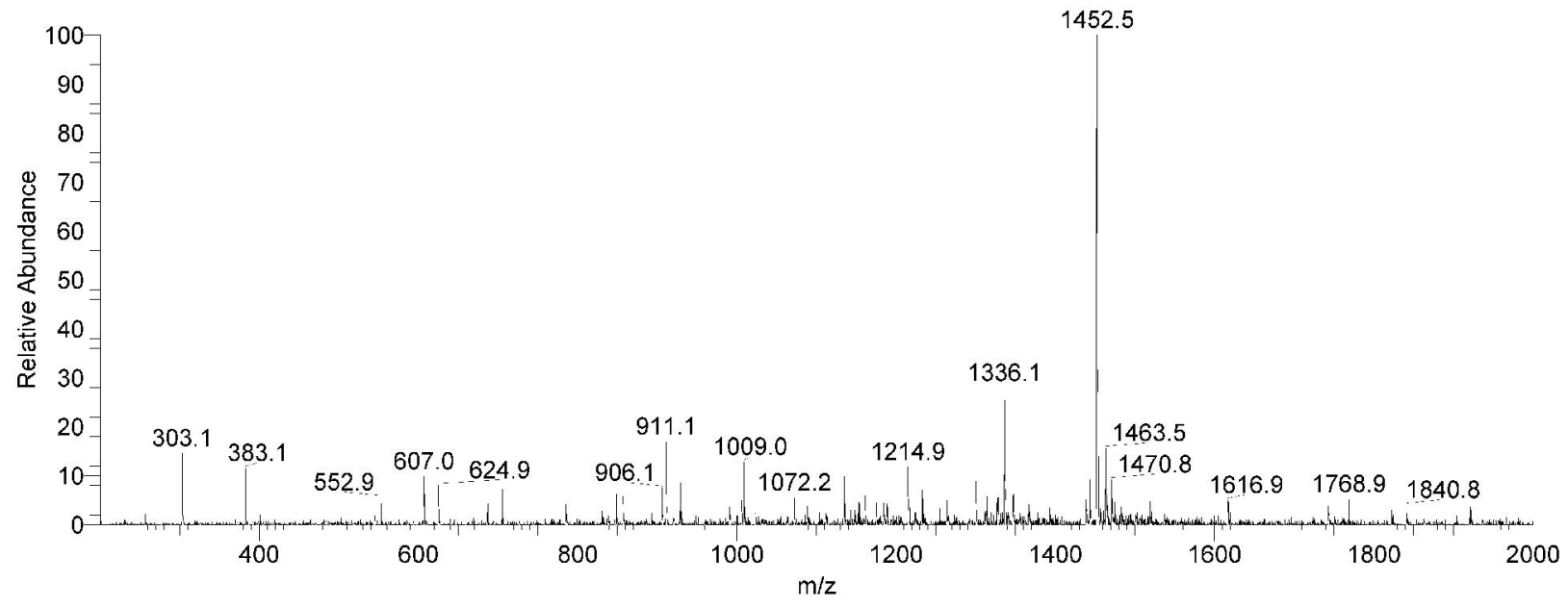

Figure 2. A) Monoisotopic half mass of dephosphorylated T9 homopolymer and B) catecholated T9 homopolymer. 

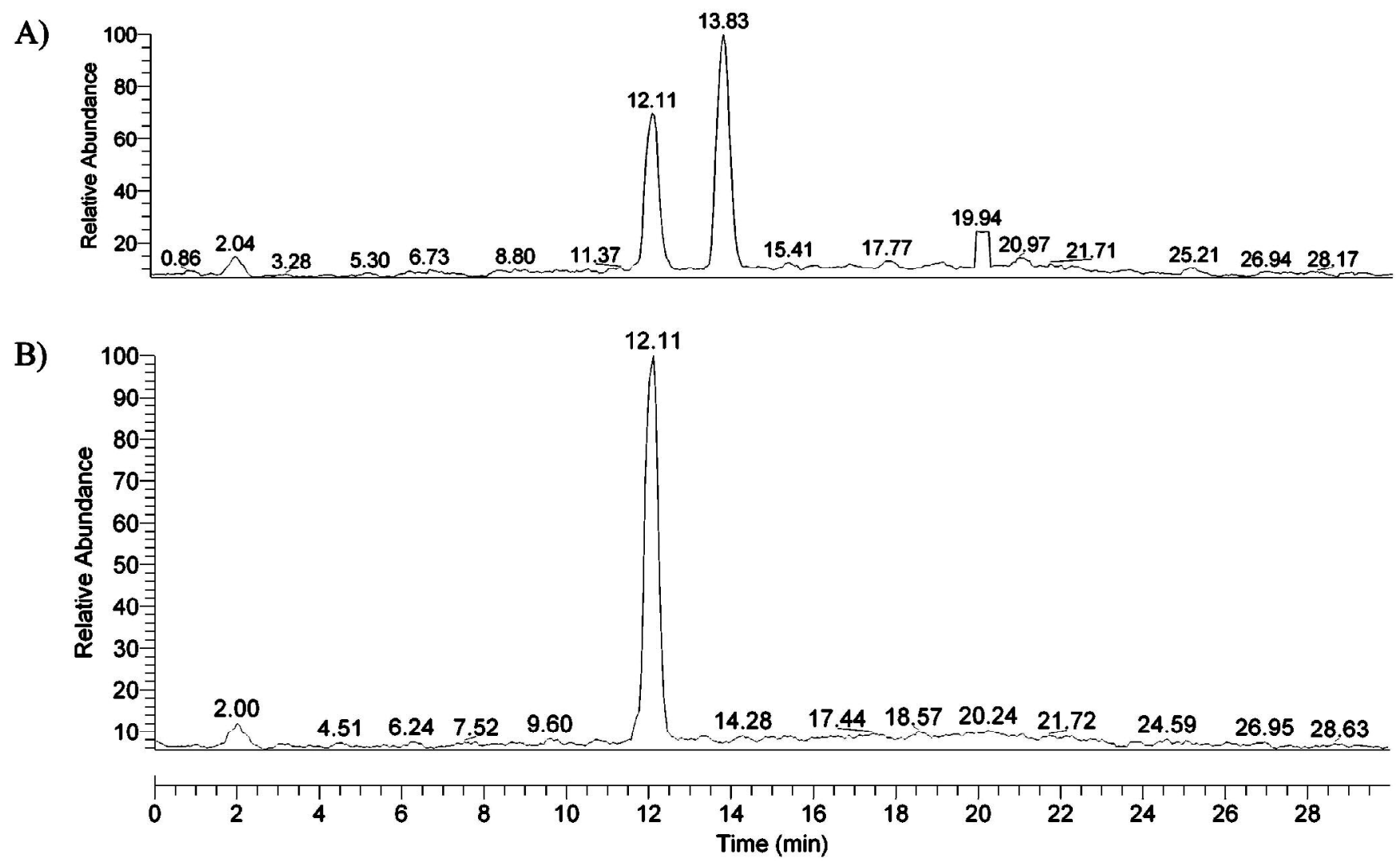

Figure 3. RP-HPLC traces of $\mathrm{T} 9$ homopolymers after treatment in $\mathrm{NH}_{4} \mathrm{OH}$ for $\mathrm{A}$ ) $1 \mathrm{hr}$ at $55^{\circ} \mathrm{C}$ and $\mathrm{B}$ ) $10 \mathrm{hrs}$ at $55^{\circ} \mathrm{C}$ show the relative abundance of catecholated and dephosphorylated species. The $10 \mathrm{hr}$ sample shows no traces of phosphorylated oligomer. 